\title{
Impact of bladder volume on treatment planning and clinical outcomes of radiotherapy for patients with cervical cancer
}

This article was published in the following Dove Press journal: Cancer Management and Research

\section{Shanshan Ma* \\ Tingting Zhang* \\ Li Jiang* \\ Wen Qin \\ Keyu Lu \\ Yong Zhang \\ Rensheng Wang}

Department of Radiotherapy, The First Affiliated Hospital of Guangxi Medical University, Nanning, Guangxi Zhuang Autonomous Region, People's Republic of China

*These authors contributed equally to this work
Correspondence: Rensheng Wang; Yong Zhang

Department of Radiotherapy, The First Affiliated Hospital of Guangxi Medical

University, 6 Shuang Yong Road, Nanning, Guangxi Zhuang Autonomous Region

53002I, People's Republic of China

$\mathrm{Tel}+867715356509$

Fax +86 77I 5323866

Email wrsgxmu@I26.com;

zhangyonggxmu@I26.com
Objective: This study aimed to investigate the impact of bladder volume on treatment planning and clinical outcomes of radiotherapy for patients with cervical cancer.

Materials and methods: One hundred and sixty-six patients with locally advanced cervical cancer were selected in this retrospective study. The patients were divided into four groups according to their average bladder volume during radiotherapy (external beam radiation therapy and intracavitary brachytherapy): group $\mathrm{A}$ : $\mathrm{V}<100 \mathrm{~mL}$, group $\mathrm{B}$ : $100 \mathrm{~mL} \leq \mathrm{V} \leq 150 \mathrm{~mL}$, group $\mathrm{C}$ : $150 \mathrm{~mL}<\mathrm{V} \leq 200 \mathrm{~mL}$, group $\mathrm{D}: \mathrm{V}>200 \mathrm{~mL}$. The bladder volume and the cumulative dose to planning target (D90), bladder (D2cc), rectum (D2cc), and sigmoid (D2cc) were calculated using the treatment planning system. Treatment outcomes including late adverse events (the maximum grade of radiation-induced proctitis and cystitis), the objective response rate of tumor and lymph node, overall survival (OS), and progression-free survival (PFS) were collected. Additionally, the correlation between bladder volume and the irradiated dose of organs at risk and treatment outcomes was analyzed.

Results: The median follow-up time was 28 months. The D90 and D2cc of the rectum in group A were the highest $(P<0.05)$. The D2cc of the bladder in group D was the highest $(P<0.05)$. There was no significant difference in the tumor and lymph node regression rate, OS, and PFS among the groups. The difference in the late radiation-induced proctitis and cystitis maximum grade among the four groups was statistically significant $(P<0.001$, $P=0.022$, respectively), with group A the most serious and group B the mildest.

Conclusion: For patients with cervical cancer, the bladder volume significantly affected the delivered dose to target, rectum, and bladder. When the bladder volume range was $100-150 \mathrm{~mL}$, the rate of late radiation-induced proctitis and cystitis was low and the degree of reaction was mild. This is thought to be the optimum bladder volume for patients with cervical cancer during radiotherapy.

Keywords: bladder volume, cervical cancer, radiotherapy, late radiation-induced injury

\section{Background}

Cervical cancer is one of the most common malignant tumors in gynecological tumors. It ranks fourth in both incidence and mortality among females worldwide; in less developed countries, its morbidity and mortality rate rank second and third, respectively, in female tumors, and socioeconomic inequality is the most notable gap. The global cancer statistics 2018 estimated that there will be 569,847 new cases and 311,365 cervical cancer death worldwide in $2018 .{ }^{11}$ Approximately $70 \%$ of cervical cancer patients were already locally advanced at the initial diagnosis, and radiotherapy-based comprehensive 
treatments are the main treatments for them. ${ }^{2}$ Because of the special anatomical position of the cervix, the bladder and rectum are close to the anterior and posterior walls of the uterus, and the tolerated dose of the bladder and rectum is lower than that of the uterus, so radiation-induced cystitis and proctitis are the most common complications. ${ }^{3}$ Most late radiation-induced cystitis occurs between 1 year and 6 years after radiotherapy, and $80 \%$ of late radiation-induced proctitis occurs between 6 months and 2 years. ${ }^{4}$ With the progress of diagnosis and treatment technology, the overall survival rate (OS) of cervical cancer has significantly improved. However, the control of radiotherapy complications has not, which seriously affects the quality of life of patients. ${ }^{5}$ In radiation therapy technology, through intensity-modulated radiation therapy, a change of position in the promotion of the adjustment of the filling degree of normal organs can effectively reduce the viscera of radioactive damage ${ }^{6-8}$ at the same time during radiotherapy, preventive use of corresponding drugs (such as radiation protective agent, intestinal flora regulator, intestinal mucosa protectant, etc.) also obtained a certain effect. $^{9,10}$ The bladder volume, as a relatively controllable influencing factor, not only changes the dose of radiotherapy, but also provides a new idea for the prevention of radiotherapy complications. Yamashita et $\mathrm{al}^{11}$ carried out a study of 10 patients with different bladder filling states $(0 \mathrm{~mL}, 50 \mathrm{~mL}$, $100 \mathrm{~mL}, 150 \mathrm{~mL}, 200 \mathrm{~mL}$ ) in the process of intracavitary brachytherapy (ICBT), and found that an increase in bladder volume resulted in a significant reduction in the hot-spot dose of the small bowel at the expense of an increase in that of the bladder without changing the dose distribution of the rectosigmoid. Many research studies confirmed that, in the process of radiotherapy, adjusting the bladder volume can change the dose of targets and organs at risk (OARs), ${ }^{12-15}$ but most of them were dosimetric studies, with outcomes such as shortterm efficacy, OS, progression-free survival rate (PFS), late radiation reaction, etc., there is no related follow-up data report, and the number of patients is deficient. Therefore, this study intends to use retrospective analysis to analyze the treatment and follow-up data of patients with cervical cancer who have received radiotherapy in our treatment center, in order to find the optimum bladder volume range which is helpful for the prognosis of patients.

\section{Materials and methods}

This study was retrospective research which analyzed the treatment and follow-up data of cervical cancer patients who were treated in our research center between January 1, 2013 and December 31, 2017. The study was approved by the First Affiliated Hospital of Guangxi Medical University Ethical Review Committee with the written informed consent of individual patients.

\section{Patients}

Eligible patients were required to meet the following inclusion criteria: patients with locally advanced cervical cancer (IB2, IIA2-IVA stage, 2009 International Federation of Gynecology and Obstetrics [FIGO] staging ${ }^{16}$ ) diagnosed for the first time; data of pelvic magnetic resonance imaging or computed tomography (CT) enhanced scan obtained before treatment, and reexamination conducted at least once during 3 months to 1 year after treatment; Karnofsky score $^{17} \geq 70$; first time of treatment for cervical cancer; treatment as recommended by National Comprehensive Cancer Network guidelines: ${ }^{18}$ radiotherapy (external beam radiation therapy (EBRT): intensity-modulated radiotherapy, DT: 45 Gy 50 Gy/25 fractions, once a day, 5 times a week; ICBT: 3D image-guided ICBT, DT: 6 Gy/5 fractions or $7 \mathrm{~Gy} / 4$ fractions); and weekly low-dose cisplatin (40 mg/ $\mathrm{m}^{2} /$ day 1) in concurrent chemoradiotherapy. Exclusion criteria were as follows: patients with other malignant tumors, pregnancy, or lactation; patients who have accepted other tumor-related treatment including radiotherapy or chemotherapy before; patients participating in clinical trials; stage IIIB patients with renal pelvis edema; and follow-up time of patients $<1$ year.

\section{Treatment planning}

All patients underwent radiotherapy and chemotherapy as described for the inclusion criteria. Varian Clinac iX linacs (Varian Medical Systems, Palo Alto, CA, USA) and the Eclipse 8.6 treatment planning system (Varian Medical Systems) were used for EBRT. Elekta Brachytherapy Solutions (Elekta, Veenendaal, The Netherlands) and the Fletcher Williamson Asia Pacific Sets (ovoid tubes and intrauterine tubes $15^{\circ}$ and $30^{\circ}$ ) were used for ICBT. During radiotherapy, patients were asked to empty their bladders $1 \mathrm{~h}$ before treatment and then drink $800 \mathrm{~mL}$ water within $10 \mathrm{~min}$ to ensure the consistency of bladder volume, and cone-beam CT was performed every 5 times of EBRT.

\section{Follow-up}

Every patient with cervical cancer in our research center was advised to review every 3-6 months within 2 years after the end of treatment, every 6-12 months within 3-5 years, and then review annually based on the patient's risk of tumor recurrence. 


\section{Methods of observation and assessment}

The treatment planning system was consulted to obtain the bladder volume (EBRT: external radiation positioning of the patient, ICBT: bladder volume in each treatment of CT images) and the cumulative dose to planning (D90) of the target, (D2cc) of the bladder, (D2cc) of the rectum, and (D2cc) of the sigmoid, as recommended by the gynecological GEC ESTRO working group. ${ }^{19,20}$ All received doses were calculated using a biologically equivalent dose of 2 Gy per fraction (EQD2) and a linear-quadratic model with $\alpha / \beta$ of 10 Gy was assumed for the target and $\alpha / \beta$ of $3 \mathrm{~Gy}$ was used for OARs. ${ }^{21-24}$ Short-term efficacy was assessed by comparing the results of gynecologic examination and/ or plain pelvic magnetic resonance imaging or CT examination before and 3 months after radiotherapy. They were classified according to WHO criteria in the evaluation of treatment response in malignant solid tumors: ${ }^{25}$ complete remission, partial response, stable disease, progression disease, and objective remission rate calculated by complete remission plus partial response. The tumor and lymph nodes were assessed, respectively. Survival results were evaluated according to the follow-up results after radiotherapy: OS and PFS were the main endpoint, and the survival time was determined from the date of diagnosis to the date of death or final follow-up. OS referred to the time from diagnosis with cervical cancer to the death of any cause. PFS referred to the time from diagnosis to progression (such as local tumor recurrence or distant metastasis) or death of any cause. Late adverse events were graded by the Radiation Therapy Oncology Group/ European Organization for Research and Treatment of Cancer (RTOG/EORTC) classification criteria, ${ }^{26}$ and the maximum-grade adverse events during follow-up were selected as the analysis data.

\section{Statistical methods}

Measurement data of the different groups were expressed as mean $\pm \mathrm{SD}$ and analyzed by ANOVA test. A chi-square test was used for the comparison of counting data. The ranksum test was used for ranking data. Univariate and multivariate analyses of prognostic factors were performed using a Cox risk model. Kaplan-Meier curves were used to analyze the patient survival rate and the log-rank test was used to analyze statistical differences among groups. All statistical analyses were performed with IBM SPSS software (version 25; IBM Corporation, Armonk, NY, USA), and a value of $P<0.05$ was considered statistically significant.

\section{Results}

\section{Patient characteristics}

A total of 184 patients with locally advanced cervical cancer met the criteria for inclusion in the study. Based on the exclusion criteria, 18 patients were excluded: 10 patients were lost during the follow-up, 2 patients were lactating, and 6 patients had stage IIIB cervical cancer with renal pelvis edema. At last, a total of 166 patients with locally advanced cervical cancer were screened, with a median age of 54 years ranging from 26 to 75 years. There were 6 cases in stage IB2, 16 cases in stage IIA2, 110 cases in stage IIB, 8 cases in stage IIIA, 23 cases in stage IIIB, and 3 cases in stage IVA. There were 145 cases of squamous cell carcinoma, 19 cases of adenocarcinoma, and 2 cases of other pathological types. There were 62 cases with positive lymph nodes and 104 cases negative. Patients were divided into four groups basing the average bladder volume during radiotherapy: group $\mathrm{A}$ : $\mathrm{V}<100 \mathrm{~mL}$, group $\mathrm{B}: 100 \mathrm{~mL} \leq \mathrm{V} \leq 150 \mathrm{~mL}$, group $\mathrm{C}: 150 \mathrm{~mL}<\mathrm{V} \leq 200$ $\mathrm{mL}$, group D: V>200 mL. A comparison of characteristics of these patients in different groups is presented in Table 1.

\section{Analysis of factors affecting OS}

Univariate analysis and multivariate analysis were performed using a Cox regression model, and determined that FIGO stage, pathology, and metastasis were all significantly associated with OS in patients with locally advanced cervical cancer (Tables 2 and 3). Interestingly, FIGO stage and pathology (adenocarcinoma) were not independent factors affecting the prognosis of locally advanced cervical cancer patients in this study.

\section{Analysis of factors affecting PFS}

Univariate analysis and multivariate analysis were performed using a Cox regression model, and determined that FIGO stage, pathology, metastasis, and recurrence were all significantly associated with PFS in patients with locally advanced cervical cancer (Tables 2 and 3 ). However, FIGO stage and pathology were not independent factors affecting the prognosis of locally advanced cervical cancer patients in this study.

\section{Analysis of dosimetry}

ANOVA test analysis of D90, D2cc of the bladder, D2cc of the rectum, and D2cc of the sigmoid found that there were statistically significant differences in D90, D2cc of the bladder, and D2cc of the rectum among the four groups. An 
Table I Clinical characteristics of patients

\begin{tabular}{|c|c|c|c|c|c|}
\hline Characteristic & Group A $(n=40)$ & Group B $(n=42)$ & Group C (n=68) & Group D $(n=16)$ & $P$ \\
\hline Age(years), Mean \pm SD & $53.55 \pm 10.76$ & $54.48 \pm 7.59$ & $53.91 \pm 8.71$ & $52.44 \pm 8.71$ & 0.418 \\
\hline KPS score, Mean \pm SD & $85 \pm 10.38$ & $84.05 \pm 11.28$ & $83.24 \pm 10.57$ & $79.38 \pm 9.29$ & 0.34 \\
\hline \multicolumn{6}{|l|}{ Pathology(n) } \\
\hline Squamous & 30 & 34 & 62 & 15 & \\
\hline Adenocarcinoma & 9 & 8 & 5 & I & \\
\hline Other patterns & 1 & 0 & I & 0 & $0.000 *$ \\
\hline \multicolumn{6}{|l|}{ FIGO stage(n) } \\
\hline IB2 & 1 & 0 & 2 & 1 & \\
\hline IIA2 & 7 & 4 & 5 & 2 & \\
\hline IIB & 14 & 31 & 55 & 10 & \\
\hline IIIA & 3 & 2 & 2 & I & \\
\hline IIIB & 15 & 3 & 3 & 2 & \\
\hline IVA & 0 & 2 & 1 & 0 & $0.000 *$ \\
\hline \multicolumn{6}{|l|}{ Pelvic LN metastasis(n) } \\
\hline Yes & 13 & 17 & 27 & 5 & \\
\hline No & 27 & 25 & 41 & 11 & $0.001 *$ \\
\hline Volume of Bladder, Mean $\pm \mathrm{SD}\left(\mathrm{cm}^{3}\right)$ & $54.61 \pm 22.39$ & $132.66 \pm 11.90$ & $172.17 \pm 15.14$ & $233.23 \pm 38.21$ & $0.000 *$ \\
\hline
\end{tabular}

Note: *Statistically significant.

Abbreviations: $n$, number; SD, standard deviation; KPS, Karnofsky's score; FIGO, International Federation of Gynecology and Obstetrics; LN, lymph node.

Table 2 Univariate analysis of prognostic factors associated with OS and PFS in patients

\begin{tabular}{|c|c|c|c|c|c|}
\hline \multirow[t]{2}{*}{ Characteristic } & \multirow[t]{2}{*}{ Group } & \multicolumn{2}{|l|}{ Overall survival } & \multicolumn{2}{|c|}{ Progression-free survival } \\
\hline & & HR (95\% Cl) & $P$ & HR (95\% CI) & $P$ \\
\hline Age & $<65$ vs $\geq 65$ & $0.917(0.119-7.071)$ & 0.933 & I.I25 (0.262-4.827) & 0.874 \\
\hline FIGO stage & I-II vs III-IVa & $4.67 \mid(1.563-13.956)$ & $0.006 *$ & $6.747(2.812-16.188)$ & $0.000 *$ \\
\hline Pathology & $\begin{array}{l}\text { Squamous } \\
\text { Adenocarcinoma } \\
\text { Other patterns }\end{array}$ & $\begin{array}{l}\text { I } \\
8.426(2.529-28.07) \\
\text { II } 17.28 \mid(|9.562-703 .| 3 \mid)\end{array}$ & $\begin{array}{l}0.000 * \\
0.001 * \\
0.000 *\end{array}$ & $\begin{array}{l}\text { I } \\
\text { II.I62 (4.529-27.507) } \\
90.56(16.82 \mid-487.55 I)\end{array}$ & $\begin{array}{l}0.000 * \\
0.000 * \\
0.000 *\end{array}$ \\
\hline Pelvic LN metastasis & Positive vs negative & $0.285(0.063-1.289)$ & 0.103 & $0.343(0.116-1.015)$ & 0.053 \\
\hline Bladder volume & $\begin{array}{l}\geq 100 \mathrm{~mL} \text { and } \leq 150 \mathrm{~mL} \\
\leq 200 \mathrm{~mL}\end{array}$ & $\begin{array}{l}\text { I } \\
0.611(0.145-2.566) \\
0.530(1.40-2.005) \\
0.453(0.053-3.890)\end{array}$ & $\begin{array}{l}0.758 \\
0.501 \\
0.350 \\
0.470\end{array}$ & $\begin{array}{l}\text { I } \\
0.863(0.319-2.331) \\
0.395(0.131-1.195) \\
0.247(0.031-1.955)\end{array}$ & $\begin{array}{l}0.250 \\
0.771 \\
0.100 \\
0.185\end{array}$ \\
\hline$D_{90}(G y)$ & $<85$ vs $\geq 85$ & $1.039(0.285-3.797)$ & 0.953 & $0.574(0.240-1.376)$ & 0.213 \\
\hline$D_{2 c c}$ of Bbadder (Gy) & $<80$ vs $\geq 80$ & $\mathrm{I} .6 \mathrm{I}(0.54-4.80 \mathrm{I})$ & 0.393 & $1.253(0.535-2.936)$ & 0.603 \\
\hline$D_{2 c c}$ of rectum (Gy) & $<65$ vs $\geq 65$ & $1.459(0.19-11.224)$ & 0.717 & I.I57 (0.270-4.956) & 0.844 \\
\hline $\mathrm{D}_{2 \mathrm{cc}}$ of sigmoid (Gy) & $<70$ vs $\geq 70$ & $0.584(0.129-2.64 I)$ & 0.485 & $0.668(0.225-1.983)$ & 0.468 \\
\hline Metastasis & Yes vs No & $18.095(6.05 \mid-54.113)$ & $0.000 *$ & $21.982(9.469-51.030)$ & $0.000^{*}$ \\
\hline Recurrence & Yes vs No & $4.465(0.978-20.384)$ & 0.053 & $|2.90|(4.808-34.616)$ & $0.000^{*}$ \\
\hline
\end{tabular}

Note: *Statistically significant.

Abbreviations: n, number; FIGO, International Federation of Gynecology and Obstetrics; LN, lymph node; HR, hazard ratio; Cl, confidence interval. 
Table 3 Multivariate analysis of prognostic factors associated with OS and PFS in patients

\begin{tabular}{|c|c|c|c|c|c|}
\hline \multirow[t]{2}{*}{ Characteristic } & \multirow[t]{2}{*}{ Group } & \multicolumn{2}{|l|}{ Overall survival } & \multicolumn{2}{|l|}{ Progression-free survival } \\
\hline & & HR (95\% Cl) & $P$ & HR (95\% Cl) & $P$ \\
\hline FIGO stage & I-II vs III-IVa & $0.537(0.116-2.477)$ & 0.425 & $0.792(0.258-2.429)$ & 0.683 \\
\hline Pathology & $\begin{array}{l}\text { Squamous } \\
\text { Adenocarcinoma } \\
\text { Other patterns }\end{array}$ & $\begin{array}{l}\text { I } \\
\text { I.920 }(0.34 \mid-10.830) \\
\text { I67.33I (I4.868-I883.256) }\end{array}$ & $\begin{array}{l}0.000^{*} \\
0.460 \\
0.000 *\end{array}$ & $\begin{array}{l}\text { I } \\
\text { I3.310 (0.430-3.993) } \\
6.701(0.964-46.592)\end{array}$ & $\begin{array}{l}0.152 \\
0.635 \\
0.055\end{array}$ \\
\hline Metastasis & Yes vs no & $20.972(2.929-150.173)$ & $0.001 *$ & $50.900(14.145-232.464)$ & $0.000 *$ \\
\hline Recurrence & Yes vs no & 1 & 1 & 38.401 (8.692-169.649) & $0.000 *$ \\
\hline
\end{tabular}

Note: *Statistically significant.

Abbreviations: $\mathrm{n}$, number; $\mathrm{HR}$, hazard ratio; $\mathrm{Cl}$, confidence interval.

Table 4 Comparative dose distribution in different groups (Mean \pm SD)

\begin{tabular}{|c|c|c|c|c|c|c|}
\hline Characteristic & Group A $(n=40)$ & Group B $(n=42)$ & Group C $(n=68)$ & Group D $(n=16)$ & Total $(n=166)$ & $P$ \\
\hline$D_{90} *$ & $97.33 \pm 11.27^{\mathrm{a}}$ & $92.79 \pm 11.28$ & $91.75 \pm 8.03$ & $87.93 \pm 9.8$ & $92.99 \pm 10.21$ & 0.006 \\
\hline $\mathrm{D}_{2 \mathrm{cc}}$ of bladder* & $74.78 \pm 13.8$ & $76.22 \pm 10.23$ & $77.74 \pm 8.75$ & $84.75 \pm\left. 12.3\right|^{b}$ & $77.32 \pm 11.10$ & 0.019 \\
\hline $\mathrm{D}_{2 \mathrm{cc}}$ of rectum* & $82.13 \pm 14.36^{c}$ & $73.58 \pm 8.69$ & $72.79 \pm 8.54$ & $75.25 \pm 8.38$ & $75.48 \pm 10.87$ & 0.000 \\
\hline $\mathrm{D}_{2 \mathrm{cc}}$ of sigmoid & $65.98 \pm 18.48$ & $61.29 \pm 12.44$ & $61.03 \pm 10.03$ & $60.50 \pm 15.27$ & $62.23 \pm 13.63$ & 0.261 \\
\hline
\end{tabular}

Note: *Statistically significant; ${ }^{2}$ There were statistical differences in $A$ and $B$ group $(P=0.04), A$ and $C$ group $(P=0.005), A$ and $D$ group $(P=0.002) ;{ }^{b}$ There were statistical difference in $A$ and $D$ group $(P=0.002), B$ and $D$ group $(P=0.008), C$ and $D$ group $(P=0.021)$; ${ }^{C}$ There were statistical difference in $A$ and $B$ group $(P=0.000), A$ and $C$ group $(P=0.000), A$ and $D$ group $(P=0.025)$. Abbreviations: $n$, number; SD, standard deviation.

independent-sample $t$-test between each group found that the mean dose of $\mathrm{D} 90$ was highest in group $\mathrm{A}$ in comparison to group $\mathrm{B}(P=0.04)$, group $\mathrm{C}(P=0.005)$, and group $\mathrm{D}(P=0.002)$. This showed a similar tendency in D2cc of the rectum: the mean dose of D2cc of the rectum in group A was the highest, and there were statistically significant differences in comparison to group $\mathrm{B}(P<0.001)$, group $\mathrm{C}(P<0.001)$, and group $\mathrm{D}$ $(P=0.025)$. We compared D2cc of the bladder among the four groups in the same way and found that there were statistically significant differences between the following groups: group A and group $\mathrm{D}(P=0.002)$, group $\mathrm{B}$ and group $\mathrm{D}(P=0.008)$, and group $\mathrm{C}$ and group $\mathrm{D}(P=0.021)$. There was no statistically significant difference in D2cc of the sigmoid among the four groups. Comparative dose distributions in the different groups are presented in Table 4. The typical dose distributions of EBRT and ICBT are shown in Figures 1 and 2.

\section{Analysis of short-term efficacy}

The objective response rate of all patients was 100\%. On analyzing results from the chi-square test, we found that there was no statistically significant difference in the rate of tumor and lymph node regression among the four groups. Comparison of efficacy variables in different groups is presented in Table 5 .

\section{Analysis of survival results}

Among 166 patients included in the study, the median follow-up time was 28 months. Thirteen patients died. Seven patients were recurrent, including three central recurrence (recurrent cervical cancer developing at the vaginal apex or in the cervix in a previously irradiated field without involving the pelvic wall ${ }^{18,27}$ ) and four noncentral recurrence (recurrent cervical cancer invaded the pelvic wall muscle or blood vessels ${ }^{18,27}$ ). Twelve patients presented metastasis; 5 patients with lung metastasis, 4 with bone metastasis, 2 with liver metastasis, and 1 with multiple systemic metastases. Kaplan-Meier survival curve analyses revealed that the average OS of these patients was $33.40 \pm 15.16$ months, with an average of $38.28 \pm 17.45$ months in group A, $31.60 \pm 14.23$ months in group B, 29.51 \pm 11.74 months in group C, and 42.44 \pm 18.42 months in group $\mathrm{D}$, respectively. The average PFS of these patients was $32.95 \pm 15.23$ months, with an average of $38.28 \pm 17.45$ months in group A, $31.60 \pm 14.2$ months in group B, 29.51 \pm 11.74 months in group $\mathrm{C}$, and $42.44 \pm 18.42$ months in group $\mathrm{D}$, respectively. There was no significant difference in long-term efficacy in these groups $(P>0.05)$. Comparison of long-term results in different groups is presented in Table 6. The OS comparison 


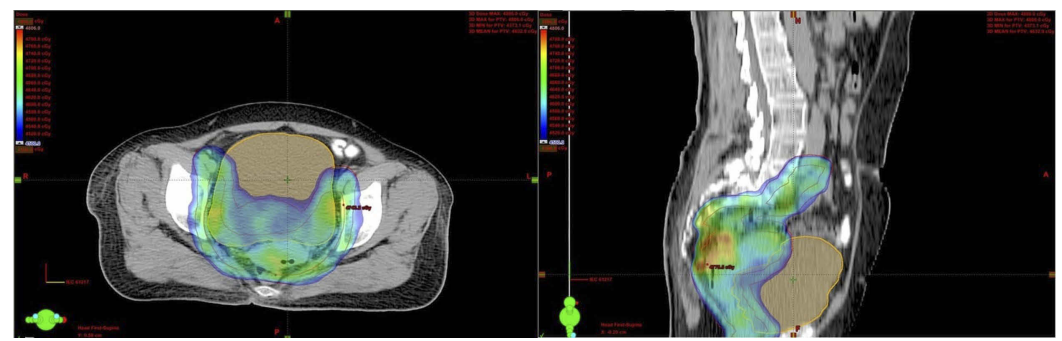

Figure I Computed tomography image showing isodose curves during external beam radiation therapy of a cervical cancer patient.

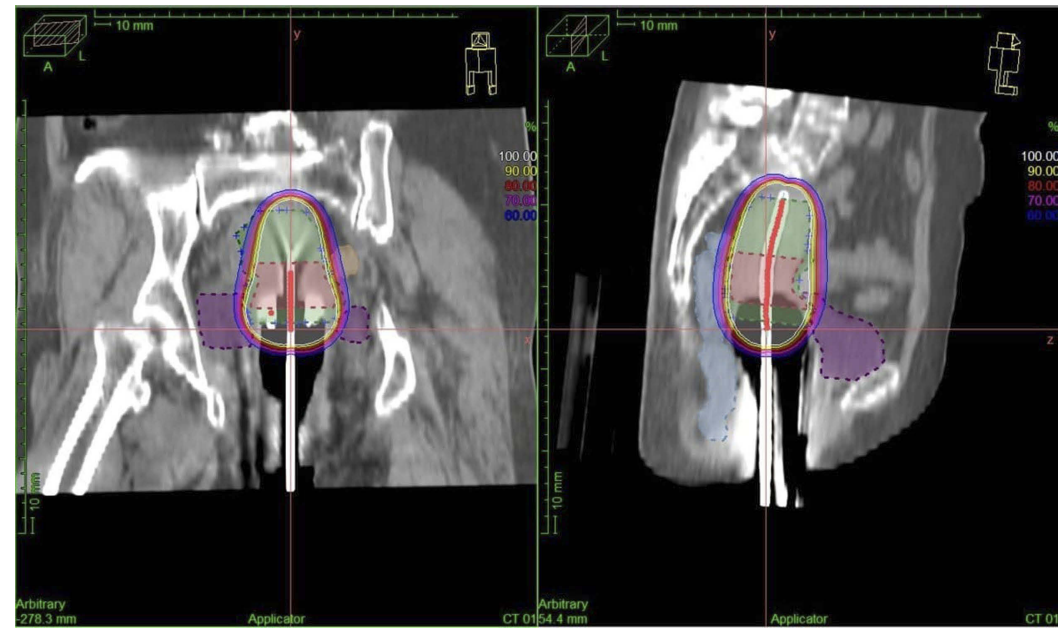

Figure 2 Computed tomography image showing isodose curves during intracavitary brachytherapy of a cervical cancer patient.

among the four groups is shown in Figure 3. The PFS comparison in the different groups is shown in Figure 4.

\section{Analysis of late radiation-induced injuries}

All of the patients in the study were followed up for at least 1 year to clarify the bladder volume influence on late radiationinduced injuries. The most common adverse events, including late radiation-induced proctitis and cystitis, were analyzed. There was no grade 4 event observed. On analyzing results of the rank-sum test of late radiation-induced proctitis and cystitis, we found that there were statistically significant differences among the four groups. The late radiationinduced proctitis was more serious in group $\mathrm{A}$ in comparison to group $\mathrm{B}(P=0.001)$ and group $\mathrm{C}(P<0.001)$. Group $\mathrm{A}$ also had the highest average rank indicating the most serious late radiation-induced injuries in the four groups. The late radiation-induced cystitis was milder in group $\mathrm{B}$ in comparison to group A $(P=0.005)$ and group $\mathrm{D}(P=0.024)$, and group $\mathrm{B}$ had the lowest average rank indicating the mildest late radiationinduced injuries in the four groups. Late maximal toxicities by RTOG/EORTC scoring in different groups are presented in Table 7.

\section{Discussion}

Radiotherapy has achieved a satisfying result in the treatment of cervical cancer, especially with the advent of novel technologies such as intensity-modulated radiation therapy, fourdimensional CT, and image guided radiation therapy, and many research studies have proved that new radiotherapy techniques improve the target doses while reducing treatment-related toxicity. ${ }^{28-31}$ However, acute and late radiationinduced proctitis and cystitis are still inevitable due to the anatomical position and physical properties of X-rays. ${ }^{32,33}$ Although radiation protectants including sulfhydryl compounds, nitroxides, antioxidant compounds, and nonantioxidant radioprotectors have been tried with some success, ${ }^{34}$ the side effects and cost-effectiveness are still important considerations for developing these agents. ${ }^{35,36}$ The method of adjusting the bladder volume to change the dose of target and OARs may be the most feasible and cost-effective approach.

A multitude of research has shown correlation between bladder volume and irradiated dose of OARs in planning ICBT for cervical cancer, but most of them were dosimetry research studies, and the influence of bladder 


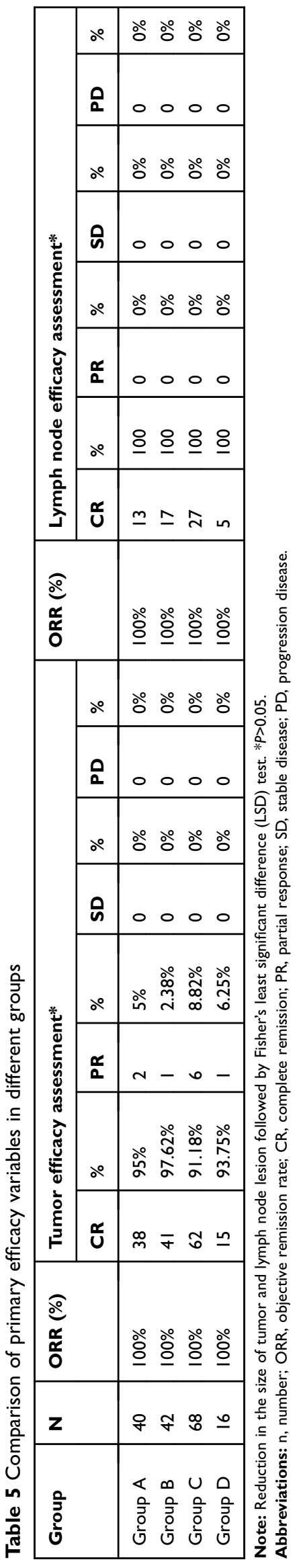

Table 6 Comparison of long-term results in different groups

\begin{tabular}{|l|l|l|l|l|}
\hline Group & N & Dead & Metastasis & Recurrent \\
\hline Group A & 40 & 5 & 4 & 3 \\
Group B & 42 & 3 & 3 & 3 \\
Group C & 68 & 4 & 4 & 1 \\
Group D & 16 & I & 1 & 0 \\
\hline
\end{tabular}

Note: There was no significant statistical difference among four groups in OS and PFS by Log Rank (Mantel-Cox) test. $P>0.05$.

volume for OARs seems to be different. Kim et $\mathrm{al}^{37}$ investigated the effects of bladder distension on OARs in the image-based planning of ICBT for 13 patients with cervical cancer, and found that an increase in bladder volume resulted in a significant reduction in bowel D2cc values at the expense of an increase in bladder D2cc values. Moreover, Nesseler et $\mathrm{al}^{38}$ investigated the point doses for OARs between an empty bladder and a full bladder $(100 \mathrm{~mL})$, and found that a negative correlation was seen between the difference in the small bowel D2ce but no differences were noted in the rectum and sigmoid colon. On the contrary, a meta-analysis ${ }^{39}$ researched the effects of different status of the bladder on dosimetry to normal tissue in brachytherapy of cervix cancer; six studies including 135 patients were involved, and the results suggested that the dose distribution to the bladder and small bowel in a filled bladder state were lower than those in an empty bladder state, and the results for the sigmoid colon and rectum were just the opposite. Consequently, in radiotherapy of cervical cancer, which OARs were affected by bladder volume and how this worked are still controversial.

For image-based treatment planning in cervical cancer, absolute volumes of 0.1 or $2 \mathrm{~cm}^{3}$ or relative volumes of $5 \%$ of the contoured OARs were evaluated as the "hot spot". The gynecological GECT ESTRO working group for image-guided brachytherapy designated the D2cc value as the surrogate for a "hot spot" of OARs. ${ }^{19}$ It was suspected that radiation-induced injury was likely caused by a hot spot in the irradiated volume. Therefore, treatment with an appropriate distended bladder may result in a significant reduction in radiation exposure to a large part of the bladder, which will be more beneficial than an empty bladder in HDR brachytherapy. In this study, we found that the dose distribution of the tumor and OARs was significantly affected by the bladder volume. D90 decreased with an increase of bladder volume, D2cc of the bladder increased with an increase of bladder volume, and there was no significant 


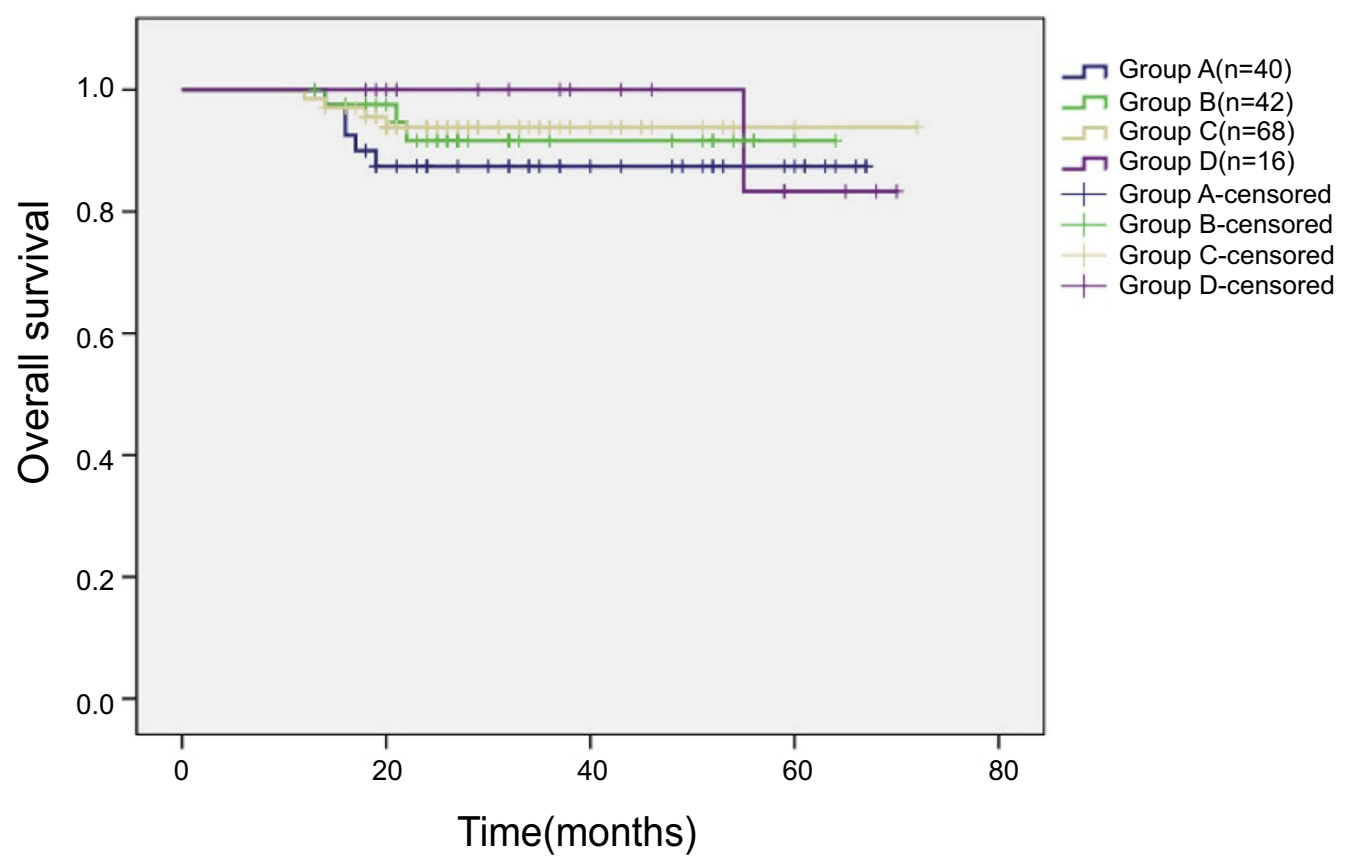

Figure 3 Overall survival comparison of the four groups (38.28 \pm 17.45 months in group $A, 31.60 \pm \mid 4.23$ months in group B, $29.51 \pm 11.74$ months in group $C$, and 42.44 \pm 18.42 months in group $D ; P>0.05$ ).

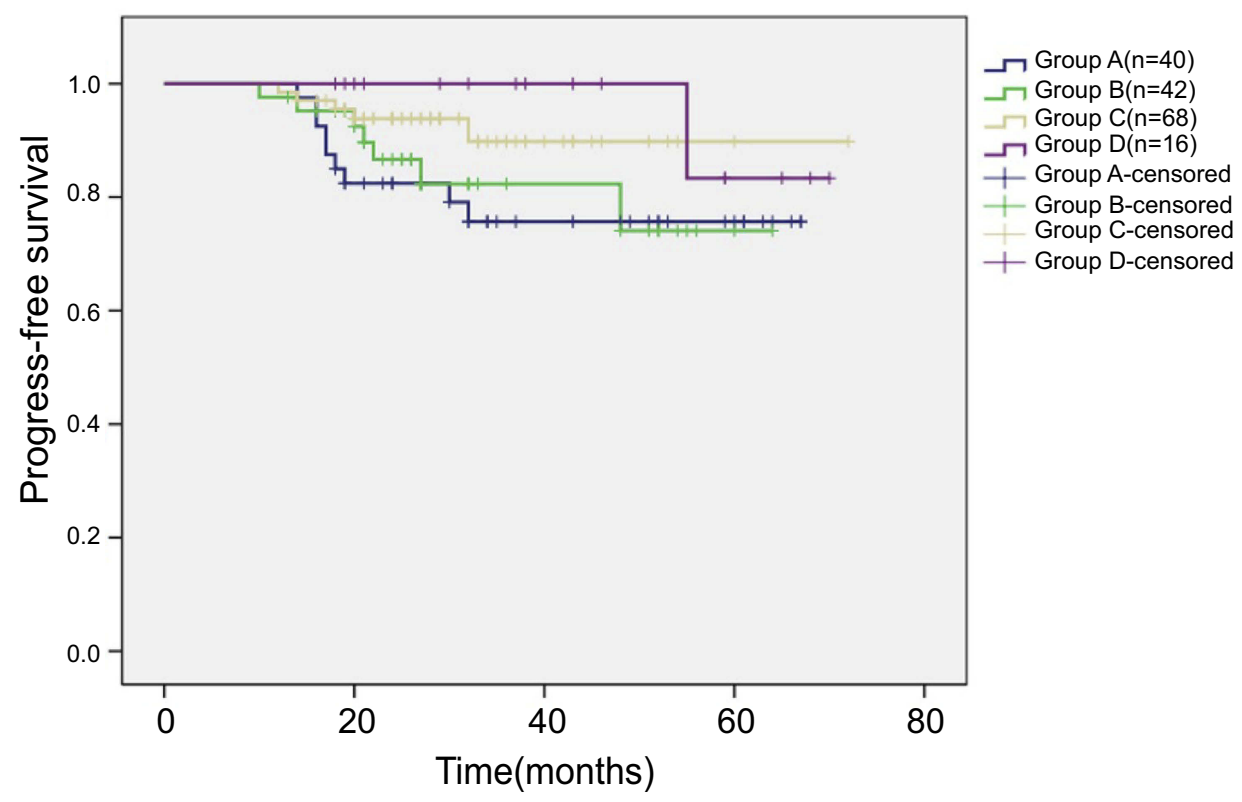

Figure 4 Progression-free survival comparison of the four groups $(38.28 \pm \mid 7.45$ months in group $A, 31.60 \pm \mid 4.2$ months in group B, $29.5 I \pm I I .74$ months in group $C$, and $42.44 \pm 18.42$ months in group $D ; P>0.05)$.

effect on D2cc of the sigmoid. Interestingly, with bladder volume $<100 \mathrm{~mL}$ or $>200 \mathrm{~mL}$, the $\mathrm{D} 2 \mathrm{cc}$ of the rectum was higher than in the other groups. We presumed that this was correlation with the anatomy position of each OAR. The excessive bladder volume forced more bladder tissue into the target area and closer to the high-dose area, leading to higher dose distribution. The rectum is behind the cervix, so the larger the bladder, the more it is pushed away from the target; but if the bladder volume is too much larger, the implant system will displace seriously and the dose of the rectum will be higher. Similarly, the location between the sigmoid and the bladder was 
Table 7 Late maximal toxicities by RTOG/EORTC scoring in different groups

\begin{tabular}{|c|c|c|c|c|c|c|c|c|c|c|c|c|c|}
\hline \multirow[t]{2}{*}{ Group } & \multirow[t]{2}{*}{$\mathbf{N}$} & \multicolumn{6}{|l|}{ Bladder*, a } & \multicolumn{6}{|l|}{ Rectum*, b } \\
\hline & & Mean Rank & 0 & I & 2 & 3 & 4 & Mean Rank & 0 & I & 2 & 3 & 4 \\
\hline Group A & 40 & 93.55 & 29 & 5 & 6 & 0 & 0 & 105.23 & 19 & 9 & 7 & 5 & 0 \\
\hline Group B & 42 & 74.46 & 40 & 1 & I & 0 & 0 & 74.52 & 35 & 3 & 4 & 0 & 0 \\
\hline Group C & 68 & 81.24 & 59 & 6 & 3 & 0 & 0 & 76.58 & 55 & 6 & 6 & I & 0 \\
\hline Group D & 16 & 91.69 & 12 & 2 & I & I & 0 & 82.16 & 12 & I & 3 & 0 & 0 \\
\hline
\end{tabular}

Note: *Statistically significant. ${ }^{a}$ There were statistical difference in $A$ and $B$ group $(P=0.005), B$ and $D$ group $(P=0.024)$; ${ }^{b}$ There were statistical difference in $A$ and $B$ group $(P=0.00 \mathrm{I})$, A and $\mathrm{C}$ group $(P=0.000)$.

Abbreviation: $n$, number.

relatively distant so its dose was not affected by the bladder volume.

Theoretically, the higher the dose of target, the better the tumor control effect will be, but with increasing D90 the dose for OARs will also increase. ${ }^{40}$ Therefore, in clinical practice, on the premise of tumor control, the protection of OARs should also be considered. In our research, the mean doses of D90 in the four groups were all higher than $85 \mathrm{~Gy}$, which already achieved the radical dose of radiotherapy for locally advanced cervical cancer recommended by the National Comprehensive Cancer Network, ${ }^{18}$ indicating that there was no impact for cervical cancer local control. The results of the Cox regression model and analysis of short-term efficacy (recession of tumor and lymph node) and the survival results (OS, PFS) in the four groups $(P>0.05)$ also proved this. Univariate analysis and multivariate analysis found that FIGO stage and pathology (adenocarcinoma) were not independent factors affecting the prognosis of locally advanced cervical cancer patients in this study, which was different from the generally known. We consider the following reasons: firstly, the included patients were locally advanced patients, and in order to observe the radiation-induced side effects we excluded the stage IIIB patients with edema of the renal pelvis. Benefiting from the progress of chemoradiotherapy, the overall treatment effect of these patients was not significantly different. Secondly, the number of nonsquamous cell carcinoma patients was smaller than the squamous patients (21 vs 145 ) and the follow-up time was not long enough, which might cause these statistical results. Therefore, we should be cautious with these results.

In this study, only proctitis and cystitis were analyzed in the late radiation-induced injuries, because the effects of dose and function on the rectum and bladder caused by changes in bladder volume are relatively common. ${ }^{41}$ It was reported that the incidence of proctitis and cystitis was $20-80 \%$ and $6-20 \%$, respectively. ${ }^{42-45}$ In our research, the incidence of proctitis and cystitis was $27.1 \%$ and $15.67 \%$, respectively, and no grade 4 event was observed, that mostly depended on the effect of advanced radiotherapy technology. Statistical results showed that the mean rank of late radiation-induced proctitis and cystitis in each group present the same trend: group $\mathrm{A}>$ group $\mathrm{D}>$ group $\mathrm{C}>$ group $\mathrm{B}$. For proctitis, this is consistent with the trend for D2cc of the rectum. However, for cystitis, this had no specific correlation with D2cc of the bladder. We speculated that within a certain dose range, the increase of bladder dose was not linearly correlated with the occurrence of side effects, and the occurrence of cystitis may be affected by a variety of factors. In addition, it took a long time to observe cystitis and the large time span of included cases also was an important interfering factor.

From what has been discussed, adjusting the volume of bladder filling may be an effective, reliable, and economical way to reduce radiation-induced proctitis and cystitis for cervical cancer during radiotherapy, and a range of $100-150 \mathrm{~mL}$ is suggested. However, some limitations of this study should be emphasized. Firstly, this was a retrospective study grouping by bladder volume range, it cannot be precise enough, the number of cases was small, and the characteristics of fully eligible patients were not similar in the four groups. Secondly, in order to clarify the late radiation-induced injuries, only patients with a follow-up time of more than 1 year were included and there was a selection bias, which may have some influence on the research results. Despite the limitations of this study, the number of cases included was still larger than other studies, and it showed a positive result for protection of OARs and might indicate a certain volume range for further research studies. Meantime, with the limitations mentioned, it is necessary to follow-up the patients and report the update results in time. In addition, well-designed prospective clinical trials with a large number of patients are needed. 


\section{Conclusion}

Bladder volume significantly affected the dose of the target, rectum, and bladder, but had no significant effect on the sigmoid. Because of the advantage of dose distribution (including dose of target and OARs) and the lowest rate of late radiationinduced proctitis and cystitis, the optimum bladder volume range is $100-150 \mathrm{~mL}$ for cervical cancer in radiotherapy. Further research is needed to determine whether patients with locally advanced cervical cancer would benefit from this bladder volume range, and whether it would alleviate acute radiation-induced injuries and other late radiation-induced complications.

\section{Acknowledgments}

This work was supported by the Research Project of Guangxi Health and Family Planning Commission (Z20180924), the Young and Middle-Aged Teachers' Basic Ability Improvement Project of Guangxi (No. 2018KY0134), the Youth Science Foundation of Guangxi Medical University (No. GXMUYSF201505), Guangxi Science and Technology Program Project (GK AD17129013), and the Central Leading Local Science and Technology Development Special Fund Project (GK ZY18076006). The funders had no role in study design, data collection and analysis, decision to publish, or preparation of the manuscript.

\section{Disclosure}

The authors report no conflicts of interest in this work.

\section{References}

1. Bray F, Ferlay J, Soerjomataram I, Siegel RL, Torre LA, Jemal A. Global cancer statistics 2018: GLOBOCAN estimates of incidence and mortality worldwide for 36 cancers in 185 countries. CA Cancer $J$ Clin. 2018;68(6):394-424. doi:10.3322/caac.21492

2. Koh WJ, Greer BE, Abu-Rustum NR, et al. Cervical cancer, version 2.2015. J Natl Compr Canc Netw. 2015;13(4):395-404; quiz 404.

3. Linn YH, Thu KK, Win N. Effect of probiotics for the prevention of acute radiation-induced diarrhoea among cervical cancer patients: a randomized double-blind placebo-controlled study. Probiotics Antimicrob Proteins. 2019;11(2):638-647.

4. Li Y, Wang L, Gao L, et al. Radiat Oncol [M]. Beijing: Peking Union Medical University Press. 2018;1406-1409.

5. Allemani C, Weir HK, Carreira H, et al. Global surveillance of cancer survival 1995-2009: analysis of individual data for 25,676,887 patients from 279 population-based registries in 67 countries (CONCORD-2). Lancet. 2015;385(9972):977-1010. doi:10.1016/S0140-6736(14)62038-9

6. Lin AJ, Kidd E, Dehdashti F, et al. Intensity modulated radiation therapy and image-guided adapted brachytherapy for cervix cancer. Int J Radiat Oncol Biol Phys. 2019;103(5):1088-1097. doi:10.1016/j. ijrobp.2018.11.012

7. Wang W, Zhang F, Hu K, Hou X. Image-guided, intensity-modulated radiation therapy in definitive radiotherapy for 1433 patients with cervical cancer. Gynecol Oncol. 2018;151(3):444-448. doi:10.1016/j. ygyno.2018.09.024
8. Lin $\mathrm{Y}$, Chen $\mathrm{K}, \mathrm{Lu} \mathrm{Z}$, et al. Intensity-modulated radiation therapy for definitive treatment of cervical cancer: a meta-analysis. Radiat Oncol. 2018;13(1):177. doi:10.1186/s13014-018-1126-7

9. Shengnan Cai KH. Advances in the treatment of radiotherapy complications of cervical cancer. Prog Obstet Gynecol. 2014;23 (7):574-576.

10. Lawrence YR, Paulus R, Langer C, et al. The addition of amifostine to carboplatin and paclitaxel based chemoradiation in locally advanced non-small cell lung cancer: long-term follow-up of Radiation Therapy Oncology Group (RTOG) randomized trial 9801. Lung Cancer. 2013;80(3):298-305. doi:10.1016/j.lungcan.2013.02.008

11. Yamashita H, Nakagawa K, Okuma K, et al. Correlation between bladder volume and irradiated dose of small bowel in CT-based planning of intracavitary brachytherapy for cervical cancer. Jpn $J$ Clin Oncol. 2012;42(4):302-308. doi:10.1093/jjco/hyr203

12. Siavashpour Z, Aghamiri MR, Jaberi R, Manshadi HR, Ghaderi R, Kirisits C. Optimum organ volume ranges for organs at risk dose in cervical cancer intracavitary brachytherapy. $J$ Contemp Brachytherapy. 2016;8(2):135-142. doi:10.5114/jcb.2016.59687

13. Bandanatham S, Gururajachar JM, Somashekar MK. Compliance with bladder protocol during concurrent chemoradiation for cancer of the cervix and its impact on enteritis: A prospective observational study. Rep Pract Oncol Radiother. 2018;23(2):69-74. doi:10.1016/j. rpor.2017.12.005

14. Shi D, Zhao Z, He M, et al. Effect of bladder volume change on normal tissue doses in 3D conformal braehytherapy for cervical cancer. Chin J Radiat Oncol. 2015;24(2):159-162.

15. Patra NB, Manir KS, Basu S, Goswami J, Kabasi AK, Sarkar SK. Effect of bladder distension on dosimetry of organs at risk in computer tomography based planning of high-dose-rate intracavitary brachytherapy for cervical cancer. J Contemp Brachytherapy. 2013;5 (1):3-9. doi:10.5114/jcb.2013.34339

16. Pecorelli S. Revised FIGO staging for carcinoma of the vulva, cervix, and endometrium. Int J Gynaecol Obstet. 2009;105(2):103-104.

17. Friendlander AH, Ettinger RL. Karnofsky performance status scale. Spec Care Dentist. 2009;29(4):147-148. doi:10.1111/j.17544505.2009.00088.x

18. NCCN. The NCCN Cervical Cancer Clinical Practice Guidelines in Oncology (version 3.2019) [EB/OL]. Fort Washington: NCCN; 2018 December 17.

19. Pötter R, Haie-Meder C, Van Limbergen E, et al. Recommendations from gynaecological (GYN) GEC ESTRO working group (II): concepts and terms in 3D image-based treatment planning in cervix cancer brachytherapy-3D dose volume parameters and aspects of 3D image-based anatomy, radiation physics, radiobiology. Radiother Oncol. 2006;78(1):67-77. doi:10.1016/j.radonc.2005.11.014

20. Haie-Meder C, Pötter R, Van Limbergen E, et al. Recommendations from Gynaecological (GYN) GEC-ESTRO Working Group (I): concepts and terms in 3D image based 3D treatment planning in cervix cancer brachytherapy with emphasis on MRI assessment of GTV and CTV. Radiother Oncol. 2005;74(3):235-245. doi:10.1016/j. radonc.2004.12.015

21. Viswanathan AN, Thomadsen B. American Brachytherapy Society Cervical Cancer Recommendations Committee, American Brachytherapy Society. American Brachytherapy Society consensus guidelines for locally advanced carcinoma of the cervix. Part I: general principles. Brachytherapy. 2012;11(1):33-46. doi:10.1016/j. brachy.2011.07.003

22. Viswanathan AN, Beriwal S, De Los Santos JF, et al. American Brachytherapy Society consensus guidelines for locally advanced carcinoma of the cervix. Part II: high-dose-rate brachytherapy. Brachytherapy. 2012;11(1):47-52. doi:10.1016/j.brachy.2011.07.002

23. Lee LJ, Das IJ, Higgins SA, et al. American Brachytherapy Society consensus guidelines for locally advanced carcinoma of the cervix. Part III: low-dose-rate and pulsed-dose-rate brachytherapy. Brachytherapy. 2012;11(1):53-57. doi:10.1016/j.brachy.2011.07.001 
24. Viswanathan ANKC, Erickson BEPR, editors. Gynecologic Radiation Therapy Novel Approaches to Image-guidance and Management. Berlin (Heidelberg): Springer-Verlag Berlin Heidelberg; 2011.

25. Miller AB, Hoogstraten B, Staquet M, Winkler A. Reporting results of cancer treatment. Cancer. 1981;47(1):207-214. doi:10.1002/10970142(19810101)47:1<207::aid-cncr2820470134>3.0.co;2-6

26. Cox JD, Stetz J, Pajak TF. Toxicity criteria of the Radiation Therapy Oncology Group (RTOG) and the European Organization for Research and Treatment of Cancer (EORTC). Int J Radiat Oncol Biol Phys. 1995;31(5):1341-1346. doi:10.1016/0360-3016(95) 00060-C

27. He M, Liu X. Advances in diagnosis and treatment of recurrent cervical cancer. J Mod Med Health. 2018;34(17):2683-2687.

28. Atiq A, Atiq M, Iqbal K, et al. A comparative study of RapidArc and intensity-modulated radiotherapy plan quality for cervical cancer treatment. Indian J Cancer. 2018;55(1):74-79. doi:10.4103/ijc. IJC_609_17

29. Jodda A, Piotrowski T, Urbański B, Malicki J. Relations between dose cumulated in organs at risk and treatment based on different image-guidance strategies of cervical cancer. Phys Med. 2019;57:183-190. doi:10.1016/j.ejmp.2019.01.008

30. Peng Q, Peng Y, Zhu J, Cai M, Zhou L. [Accuracy of different image registration methods in image-guided adaptive brachytherapy for cervical cancer]. Nan Fang Yi Ke Da Xue Xue Bao. 2018;38 (11):1344-1348. doi:10.12122/j.issn.1673-4254.2018.11.11

31. Simha V, Rai B, Patel FD, et al. Clinical outcomes with MRI-guided image-based brachytherapy in cervical cancer: an institutional experience. Brachytherapy. 2018;17(2):345-351. doi:10.1016/j. brachy.2017.09.008

32. Wang Y, Kong W, Lv N, et al. Incidence of radiation enteritis in cervical cancer patients treated with definitive radiotherapy versus adjuvant radiotherapy. J Cancer Res Ther. 2018;14(Supplement): S120-S124. doi:10.4103/0973-1482.163762

33. Yang X, Wang J, Lin L, Gao D, Yin L. Concomitant chemoradiotherapy versus pure radiotherapy in locally advanced cervical cancer: a retrospective analysis of complications and clinical outcome. Eur $J$ Gynaecol Oncol. 2016;37(4):499-503.

34. Small W Jr. Potential for use of amifostine in cervical cancer. Semin Oncol. 2002;29(6 Suppl 19):34-37. doi:10.1053/sonc. 2002.37366

35. Kuruba V, Gollapalli P. Natural radioprotectors and their impact on cancer drug discovery. Radiat Oncol J. 2018;36(4):265-275. doi:10.3857/roj.2018.00381
36. Lee MG, Freeman AR, Roos DE, Milner AD, Borg MF. Randomized double-blind trial of amifostine versus placebo for radiation-induced xerostomia in patients with head and neck cancer. $J$ Med Imaging Radiat Oncol. 2019;63(1):142-150. doi:10.1111/jmiro.2019.63.issue-1

37. Kim RY, Shen S, Lin H-Y, Spencer SA, De Los Santos J. Effects of bladder distension on organs at risk in 3D image-based planning of intracavitary brachytherapy for cervical cancer. Int J Radiat Oncol Biol Phys. 2010;76(2):485-489. doi:10.1016/j.ijrobp.2009.02.002

38. Nesseler JP, Charra-Brunaud C, Salleron J, et al. Effect of bladder distension on doses to organs at risk in Pulsed-Dose-Rate 3D imageguided adaptive brachytherapy for locally advanced cervical cancer. Brachytherapy. 2017;16(5):976-980. doi:10.1016/j.brachy.2017.06.003

39. Fu T, Xu W, Xu S, et al. Effects of different status of the bladder on dosimetry to normal tissue in brachytherapy of Cervix Cancer: a meta-analysis. Chin J Radiat Oncol. 2016;25(7):718-723.

40. Pötter R, Georg P, Dimopoulos JC, et al. Clinical outcome of protocol based image (MRI) guided adaptive brachytherapy combined with $3 \mathrm{D}$ conformal radiotherapy with or without chemotherapy in patients with locally advanced cervical cancer. Radiother Oncol. 2011;100 (1):116-123. doi:10.1016/j.radonc.2011.07.012

41. Lee H, Huh SJ, Oh D, Jeong BK, Ju SG. Radiation sigmoiditis mimicking sigmoid colon cancer after radiation therapy for cervical cancer: the implications of three-dimensional image-based brachytherapy planning. J Gynecol Oncol. 2012;23(3):197-200. doi:10.3802/jgo.2012.23.3.197

42. Ma Y, Zhao G, Qi J, et al. Neoadjuvant brachytherapy and chemotherapy followed by radical surgery for stage IB2 and IIA cervical cancer: a retrospective comparison with chemoirradiation. Mol Clin Oncol. 2018;8(4):623-627. doi:10.3892/mco.2018.1580

43. Wang YM, Wang CJ, Fang FM, et al. Differences in the outcomes and complications between elderly and younger uterine cervical cancer patients treated by definitive radiotherapy - a propensity score-matched study. Gynecol Oncol. 2017;145(2):277-283. doi:10.1016/j. ygyno.2017.02.034

44. Allen S, Kilian C, Phelps J, Whelan HT. The use of hyperbaric oxygen for treating delayed radiation injuries in gynecologic malignancies: a review of literature and report of radiation injury incidence. Support Care Cancer. 2012;20(10):2467-2472. doi:10.1007/s00520-012-1379-x

45. Novetsky AP, Einstein MH, Goldberg GL, et al. Efficacy and toxicity of concomitant cisplatin with external beam pelvic radiotherapy and two high-dose-rate brachytherapy insertions for the treatment of locally advanced cervical cancer. Gynecol Oncol. 2007;105(3):635640. doi:10.1016/j.ygyno.2007.01.032
Cancer Management and Research

\section{Publish your work in this journal}

Cancer Management and Research is an international, peer-reviewed open access journal focusing on cancer research and the optimal use of preventative and integrated treatment interventions to achieve improved outcomes, enhanced survival and quality of life for the cancer patient.
The manuscript management system is completely online and includes a very quick and fair peer-review system, which is all easy to use. Visit http://www.dovepress.com/testimonials.php to read real quotes from published authors. 